\title{
PEMBELAJARAN METODE DIROSA DI DESA MAJANNANG KABUPATEN GOWA
}

\author{
Hendra Wijaya \\ Sekolah Tinggi Ilmu Islam dan Bahasa Arab (STIBA) Makassar \\ hendrawijaya@stiba.ac.id \\ Nurhidayah \\ Sekolah Tinggi Ilmu Islam dan Bahasa Arab (STIBA) Makassar \\ nurhidayah@gmail.com
}

Keywords :

Alquran, Adults, Dirosa,

Tajweed, KKN STIBA.

\begin{abstract}
Koran Education for Adult (Dirosa) was one well-known program of students of Community Service Program (KKN) of STIBA Makassar held in Majannang village, Parigi District, Gowa Regency, South Sulawesi Province. The objectives of this program were; (1) To increase enthusiasm in learning and teaching the Koran for teenagers and adults, (2) To provide teenagers and adults learning for reading Koran so that they can read it according to the knowledge of recitation. (3) To provide additional knowledge of the basics of Islam for teenagers and adults. The implementation of Dirosa program in Majannang village was of 7 study groups, with details: 2 groups of men, 2 groups of women, and 3 groups of young men. The number of participants initially was 59 people and has succeeded in resulting as many as 23 alumni who consistently attended 20 meetings. Most participants before participating Dirosa program did not read the Koran fluently, neither do they understand the knowledge of recitation, and there were among them who were illiterate in the Koran, after participating in Dirosa program they became proficient in reading the Koran according to the principles of recitation, people of Majannang village also received additional knowledge about Islamic insights, especially those which are related to Islamic practices of worship and morality.
\end{abstract}

\begin{abstract}
Pendidikan Alquran Orang Dewasa (DIROSA) merupakan salah satu program unggulan mahasiswa KKN STIBA Makassar Angkatan III yang diselenggarakan di desa Majannang, Kecamatan Parigi, Kabupaten Gowa, Provinsi Sulawesi Selatan. Tujuan program ini adalah; (1) Untuk meningkatkan semangat dalam mempelajari dan mengajarkan Alquran bagi remaja dan orang dewasa, (2) Untuk Memberikan pembelajaran baca Alquran kepada remaja dan orang dewasa agar dapat membaca sesuai ilmu tajwid. (3) Memberikan tambahan ilmu dasar-dasar keislaman kepada remaja dan orang dewasa. Pelaksanaan program DIROSA di desa Majannang terdiri dari 7 kelompok belajar, dengan rincian; 2 kelompok belajar bapakbapak, 2 kelompok belajar ibu-ibu dan 3 kelompok remaja putra. Jumlah peserta awal sebanyak 59 orang dan telah berhasil mencetak sebanyak 23 alumni, yaitu alumni yang konsisten menghadiri 20 kali pertemuan. Sebagian besar peserta sebelum mengikuti program DIROSA belum lancar membaca Alquran, tidak paham kaidah
\end{abstract}


WAHATUL MUJTAMA': Jurnal Pengabdian Masyarakat

Vol. 1, No. 1 (2020) : Hal. 67-74

Website: https://journal.stiba.ac.id

tajwid dan bahkan diantara peserta ada yang buta aksara Alquran, setelah mengikuti program DIROSA peserta menjadi mahir membaca Alquran sesuai kaidah tajwid, masyarakat desa majannang juga mendapat tambahan ilmu tentang wawasan keislaman, khususnya yang terkait praktik ibadah dan akhlak islami. 
WAHATUL MUJTAMA': Jurnal Pengabdian Masyarakat

Vol. 1, No. 1 (2020) : Hal. 67-74

Website: https://journal.stiba.ac.id

\section{PENDAHULUAN}

Sekolah Tinggi Ilmu Islam dan Bahasa Arab (STIBA) Makassar merupakan institusi Perguruan Tinggi Agama Islam yang berkonsentrasi pada pengaderan dai dan ulama, yang mana salah satu misi utama dari intitusi ini adalah menyebarkan ajaran Islam berdasarkan tuntunan Alquran dan Sunnah sesuai pemahaman Al-Salafusshalih melalui gerakan dakwah yang dipelopori oleh para ahlul ilmi. ${ }^{1}$ Maka dalam rangka mewujudkan misi tersebut, STIBA Makassar kemudian menjabarkan misinya secara teknis dalam program-program pengabdian kepada masyarakat, diantaranya dalam bentuk Kuliah Kerja Nyata $(\mathrm{KKN})$ berbasis riset.

Program KKN merupakan salah satu bentuk kegiatan perkuliahan yang dilakukan di lapangan yang berorientasi pada pembelajaran dan pemberdayaan masyarakat, ${ }^{2}$ program ini sebagai bentuk nyata keterlibatan institusi STIBA Makassar dalam upaya menumbuh kembangkan kesadaran religius yang menjadi cita-cita STIBA Makassar. Program KKN STIBA Makassar dilaksanakan sekali dalam setahun, tepatnya diawal semester genap yaitu pada interval waktu antara bulan januari sampai dengan bulan maret, Program KKN diikuti oleh mahasiswa yang telah memenuhi semua persyaratan dan ditetapkan oleh Bidang Akademik STIBA Makassar yang berkoordinasi dengan Pusat Penelitian dan Pengabdian kepada Masayarakat (P3M) STIBA Makassar. ${ }^{3}$

Pada program KKN angkatan III tahun akademik 2019-2020, STIBA Makassar mengutus 21 Mahasiswa ke Desa Majannang, Kecamatan Parigi, Kabupaten Gowa, Provinsi Sulawesi Selatan. Program KKN di Desa Majannang ini dibagi menjadi dua posko, posko 01 berlokasi di rumah bapak Muh. Nuru' Panai di RT 01 RW Bajannang, posko ini beranggotakan 9 mahasiswa (putra) yaitu Ahmad (Koordinator Desa), Fikriansyah Tjarsadiwiryo, Khalid Hamrullah, Tholhah, Fikri Rahman, Rabbil, Rachmad Mulyadi, Rahmat Ramadan Usman, Sulkifli. Posko 02 di rumah bapak Daeng Nannang Laco', RT 01 RW Putepala, anggota posko beranggotakan beranggorakan 12 orang Mahasiswi (putri) yaitu Sri Devi (Wakil Koordinator Desa), Astri Nuzul Ramadhani, Kurnia, Neli, Mawaddah Warahmah,Musdalifah, Mutmainnah A., Nur Izzatul Haq, Nur Amiratun Khairiyyah, Mirawati, Rahmawati, Rosnia R.

Desa Majannang merupakan salah satu dari 5 desa yang ada di wilayah administratif Kecamatan Parigi, desa Majannang terdiri dari 3 dusun yaitu Dusun Nirannuang, Dusun Longka, dan Dusun Sironjong. Secara geografis Desa Majannang berada di ketinggian antara 500-800 dpl (diatas permukaan laut). Dengan keadaan curah

\footnotetext{
1 Sekolah Tinggi Ilmu Islam dan Bahasa Arab (STIBA) Makassar, Visi misi, https://stiba.ac.id//tentangstiba/visi-misi/ (9 April 2020)

${ }^{2}$ P3M STIBA Makassar. Buku Panduan KKN STIBA Makassar Angkatan II Tahun 1440 H/ 2018 M (Makassar: STIBA Makassar, 2018), h.3.

${ }^{3}$ Tim Penyusun. Buku Panduan KKN STIBA Makassar Angkatan II Tahun 1440 H/2018 M, h.3

Hendra Wijaya, Nurhidayah. Pembelajaran Metode Dirosa ... 
hujan rata-rata dalam pertahun antara 32-35 mm per tahun yang berkisar 135 hari s/d 160 hari dengan suhu rata-rata pertahun adalah $20 \mathrm{~s} / \mathrm{d} 23^{\circ} \mathrm{C}$.

Bahasa yang digunakan pada umumnya oleh masyarakat desa adalah bahasa daerah Makassar, menurut data statistik Kabupaten Gowa tahun 2019, jumlah penduduk yang beragama Islam mencapai angka 100\% yaitu sebanyak 2.812, dengan jumlah rumah ibadah 12 Masjid dan 4 Musalla. ${ }^{4}$ Mata pencaharian utama masyarakat Majannang sebagai petani utamanya pertanian sawah atau tanaman pangan lainnya, sedangkan sektor non pertanian bergerak pada lapangan usaha perdagangan besar maupun eceran, sebagian lainnya bergelut dibidang pemerintahan dan berstatus PNS, sebagian lainnya berprofesi sebagai tukang, sopir, buruh tani, buruh bangunan, tukang kayu dan tukang batu, guru honor dan lain sebagainya. Salah satu program unggulan KKN desa Majannang yang mendapat sambutan hangat oleh masyarakat Majannang khususnya kalangan remaja dan orang dewasa adalah program Pendidikan Alquran Orang Dewasa, disingkat DIROSA ${ }^{5}$.

DIROSA merupakan sebuah metode praktis pengajaran membaca Alquran yang diperuntukkan khusus kepada kaum remaja dan orang tua, program ini berjalan secara dinamis dan sistematis, dilaksanakan selama kurung waktu tertentu dengan materi yang berjenjang, Metode Dirosa merupakan penggabungan pola pengajaran membaca alQur'an dan ilmu-ilmu keislaman. ${ }^{6}$

\section{PEMBAHASAN}

Tujuan pelaksanaan program DIROSA dalam pelaksanaan KKN STIBA Makassar di Desa Majannang adalah; (1) Meningkatkan semangat dalam mempelajari dan mengajarkan Alqur'an bagi remaja dan orang dewasa, (2) Memberikan pembelajaran baca Alqur'an kepada remaja dan orang dewasa agar dapat membaca Alqur' an sesuai ilmu tajwid. (3) Memberikan tambahan ilmu dasar-dasar keislaman kepada remaja dan orang dewasa. Dalam rangka memaksimalkan pelaksanaan program DIROSA, maka seluruh mahasiswa KKN STIBA Makassar mendapat pembekalan khusus mengenai metode pengajaran DIROSA, pembekalan dilaksanakan sebelum pengutusan di lokasi KKN dengan mendatangkan praktisi DIROSA. Mahasiswa KKN menerima materi praktis pengajaran metode DIROSA dan modul pembelajarannya. Pengajaran DIROSA dilaksanakan dengan model klasikal dengan membentuk kelompok-kelompok belajar, setiap kelompok belajar umumnya berkisar antara 5 sampai dengan 15 orang.

Metode pembelajaran menggunakan tehnik baca-tunjuk-simak-ulang pada modul khusus DIROSA setebal 72 Halaman, yaitu pembina membacakan bahan materi yang ada

\footnotetext{
${ }^{4}$ Badan Pusat Statistik Kabupaten Gowa, Kecamatan Parigi dalam Angka Tahun 2019 (Gowa: t.p 2019): h.12-29.

${ }^{5}$ Komari, S.Pd dan Dra. Sunarsih, Panduan Belajar Baca Alquran Sistem Klasikal 20 Pertemuan DIROSA, (Bogor; Yayasan Cita Mulia Mutiara 2018): h.1.

6 Muhammad Saddang, Achmad Abu Bakar, Munir. Implementasi Metode DIROSA dalam Pembelajaran Al-Qur'an Dewan Pimpinan Daerah Wahdah Islamiyah Makassar, (Makassar: Jurnal Diskursus Islam, Vol.6, N0.3 (2018): h.486.
} 
pada modul, kemudian peserta menunjuk tulisan sembari mendengarkannya dengan seksama. setelah itu peserta mengulangi bacaan yang telah disimaknya, Teknik bacatunjuk-simak-ulang ini dilaksanakan disetiap pertemuan dengan beberapa variasi yang dijelaskan dalam panduan pengajaran dalam modul, pembelajaran DIROSA juga dapat menggunakan alat peraga berupa papan tulis atau poster bertuliskan huruf-huruf hijaiyah, program DIROSA ditamatkan selama 20 kali pertemuan, tiap pertemuan disajikan kurang lebih 60 sampai dengan 90 menit atau disesuaikan dengan kebutuhan.

Tahap awal program DIROSA dilaksanakan dengan cara mensosialisasikan kepada komunitas-komunitas masyarakat desa Majannang sekaligus penawaran pembelajaran DIROSA dalam bentuk kelompok belajar. Program DIROSA ini mendapat sambutan hangat dibeberapa tempat dan komunitas diantaranya di SMP 1 Parigi, SMA12 Gowa, Masjid Babul Khair Bajannang, Masjid Nurussalam Sampeang, Majelis Taklim Ibu-ibu Masjid Bontorappo, Orang tua murid TK Tunas Sejahtera. Hasil dari sosialisasi tersebut yaitu terbentuknya 7 kelompok belajar, dengan rincian; 2 kelompok belajar bapak-bapak, 2 kelompok belajar ibu-ibu dan 3 kelompok remaja putra. Total peserta yang terdaftar sebanyak 59 peserta tetap.

Pembina sekaligus penanggung jawab program ini berjumlah 4 orang Pembina dari anggota KKN STIBA Angkatan III desa Majannang yaitu Fikriansyah, Rahmad Mulyadi, Rabbil dan Musdalifah, sedangkan mahaiswa/i lainnya menjadi tenaga pengajar pembantu, yang selalu siap sedia khususnya pada pembinaan DIROSA di SMP 1 Parigi dan SMA 12 Gowa, dengan jadwal pembelajaran sebagai berikut;

\begin{tabular}{|c|c|c|c|c|c|}
\hline No & Jam & Hari & Tempat & Pembina & Ket. \\
\hline 1 & $\begin{array}{l}18.30- \\
20.00\end{array}$ & $\begin{array}{l}\text { Selasa, Kamis, } \\
\text { Ahad }\end{array}$ & $\begin{array}{l}\text { Masjid Babul } \\
\text { Khair, } \\
\text { Bajannang }\end{array}$ & Fikriansyah & $\begin{array}{l}1 \text { Kelompok } \\
\text { Belajar }\end{array}$ \\
\hline 2 & $\begin{array}{l}18.30- \\
20.00\end{array}$ & $\begin{array}{l}\text { Senin dan } \\
\text { Rabu }\end{array}$ & $\begin{array}{l}\text { Masjid } \\
\text { Nurussalam, } \\
\text { Sampeang }\end{array}$ & $\begin{array}{l}\text { Rachmad } \\
\text { Mulyadi \& } \\
\text { Rabbil }\end{array}$ & $\begin{array}{l}1 \text { Kelompok } \\
\text { Belajar }\end{array}$ \\
\hline 3 & Insidentil & $\begin{array}{l}\text { Senin dan } \\
\text { Jumat }\end{array}$ & SMA 12 Gowa & Fikriansyah & $\begin{array}{l}\text { Pada Jam } \\
\text { Sekolah, di } \\
\text { kelas yang } \\
\text { jam } \\
\text { pelajaranny } \\
\text { a kosong }\end{array}$ \\
\hline 4 & $\begin{array}{l}08.00- \\
09.30\end{array}$ & Jumat & SMP 1 Parigi & Fikriansyah & $\begin{array}{l}3 \text { Kelompok } \\
\text { Belajar }\end{array}$ \\
\hline 5 & $\begin{array}{l}09.00- \\
11.00\end{array}$ & Senin-Sabtu & $\begin{array}{l}\text { TK Tunas } \\
\text { Sejahtera }\end{array}$ & Musdalifah & $\begin{array}{l}\text { Peserta } \\
\text { adalah } \\
\text { orang tua } \\
\text { murid TK } \\
\text { Tunas }\end{array}$ \\
\hline
\end{tabular}




\begin{tabular}{|c|c|c|c|c|c|}
\hline & & & & & $\begin{array}{l}\text { Sejahtera/ } 1 \\
\text { Kelompok } \\
\text { Belajar }\end{array}$ \\
\hline 6 & $\begin{array}{l}05.00- \\
06.00\end{array}$ & Senin-Sabtu & $\begin{array}{l}\text { Masjid } \\
\text { Bontorappo }\end{array}$ & Musdalifah & $\begin{array}{l}\text { Jemaah Ibu- } \\
\text { ibu/ } 1 \\
\text { Kelompok } \\
\text { Belajar }\end{array}$ \\
\hline
\end{tabular}

Proses pembelajaran dibagi menjadi 4 tahapan dengan durasi antara 60 sampai 90 menit. Berikut masing-masing uraian setiap tahap.

Tahap pertama adalah pembukaan, dalam tahapan ini pembina memberi nasehat tentang keutamaan belajar dan mengajarkan Alquran, pembukaan dilakukan kurang lebih 15 Menit.

Tahap kedua adalah pelajaran inti, yaitu proses belajar membaca Alquran dengan tehnik baca-tunjuk-simak-ulang dengan berbagai variasinya, tahapan ini dilaksanakan kurang lebih 45 menit, tahap ketiga materi keislaman dan tanya-jawab tentang Islam dilaksanakan sekitar 15 menit, kemudian tahapan terahir adalah penutup yang berdurasi kurang lebih 15 menit yaitu pembina kembali memberikan motivasi untuk konsisten menghadiri majelis ilmu, kemudian diakhiri dengan doa penutup majelis.

Pada pertemuan-pertemuan awal, yaitu pertemuan pertama sampai pertemuan ke5 peserta merasa kesulitan dalam penyebutan huruf demi huruf, begitupula dalam mempraktekkan nada bacaaan khusus yang dipakai dalam pembelajaran metode DIROSA, pada pertemuan ke 6 sampai ke-10 peserta sudah mulai mengenal huruf huruf hijaiyah dengan baik dan lancar dan mulai beradaptasi dengan nada bacaan DIROSA, Pertemuan ke 11 sampai 15 bacaan peserta semakin baik dan lancar, namun karena bertepatan dengan musim tanam padi, membuat beberapa dari mereka khususnya peserta ibu-ibu dengan berat hati meninggalkan proses belajar DIROSA, kemudian pada pertemuan 16 sampai 20 peserta sudah mulai berkenalan dengan hukum-hukum tajwid, jumlah peserta aktif pun sudah mulai stabil.

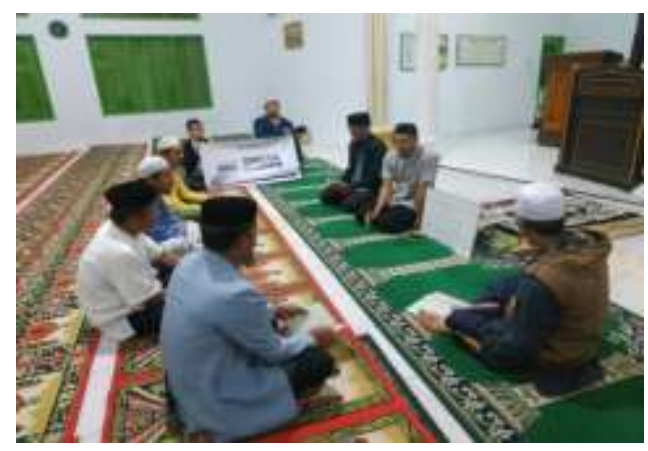

Gambar 1.1. Kelompok Belajar di Masjid Nurussalam, Sampeang. 
Sebagian besar peserta pada awalnya tidak lancar membaca Alquran, membaca Alquran dengan cara terbata-bata, atau bahkan sama sekali tidak memahami kaidah tajwid, ada pula beberapa peserta tergolong buta aksara Alquran, tidak mampu sama sekali mengeja huruf hijaiyah.

Setelah mengikuti program DIROSA peserta menjadi lancar membaca Alquran sesuai kaidah tajwid, selain mahir membaca Alquran, masyarakat desa majannang yang mengikuti program DIROSA juga mendapat tambahan ilmu berupa wawasan keislaman, khususnya yang terkait praktik ibadah dan akhlak islami. Alumni program ini juga berhak mendapat sertifikat DIROSA dan hadiah souvenir dari Mahasiswaa KKN STIBA Makassar.

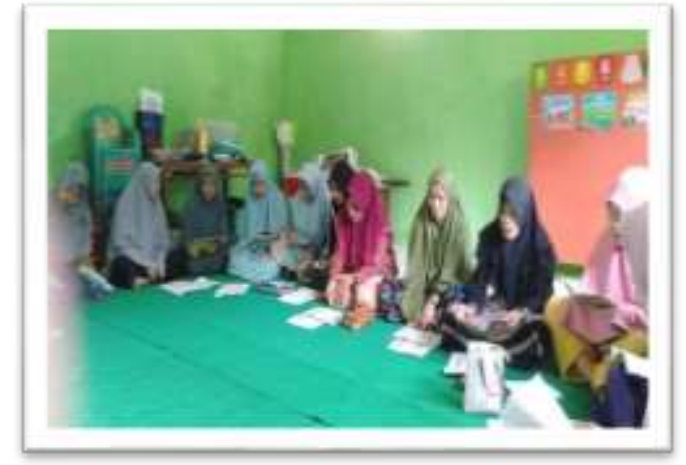

\section{Gambar 1.2. Pembagian Sertifikat dan Souvenir kepada Alumni}

Dari 59 peserta terdaftar program DIROSA, yang berhasil bertahan sampai tahap akhir selama 20 kali pertemuan berjumlah 40\% dari jumlah keselurahan peserta awal, tepatnya berjumlah 23 alumni program DIROSA, ini berarti terdapat $60 \%$ peserta yang tidak dapat melanjutkan program DIROSA sampai tahap akhir, hal ini disebabkan beberapa hal diantaranya; 1) Kegiatan pembelajaran bertepatan dengan musim tanam padi yang menyebabkan sebagian masyarakat tidak sempat mengikuti pembelajaran; 2) Sebagian besar masyarakat dari kalangan orang tua, merasa malu-malu untuk mengikuti pembelajaran DIROSA.

Sebagai solusi permasalahan ini Mahasiswa KKN perlu; 1) berupaya mencari waktu yang tepat bagi masyarakat petani khususnya dimusim tanam padi, serta berupaya menyesuaikan waktu pembina dengan waktu peserta; 2) berupaya terus memberikan penguatan kepada masyarakat tentang perlunya menuntut ilmu terkhusus dalam mempelajari Alquran.

\section{KESIMPULAN}

Program DIROSA merupakan program unngulan KKN STIBA Makassar Angkatan III di desa majannang yang diperuntukkan untuk orang dewasa dan remaja. Program ini berhasil mencetak 23 alumni dari 59 peserta terdaftar, peserta tersebar di 7 kelompok belajar. Sebagian besar peserta sebelum mengikuti program DIROSA belum 
WAHATUL MUJTAMA': Jurnal Pengabdian Masyarakat

Vol. 1, No. 1 (2020) : Hal. 67-74

Website: https://journal.stiba.ac.id

lancar membaca Alquran, tidak paham kaidah tajwid dan bahkan diantara peserta ada yang buta aksara Alquran, setelah mengikuti program DIROSA peserta menjadi mahir membaca Alquran sesuai kaidah tajwid, masyarakat desa majannang juga mendapat tambahan tentang wawasan keislaman, khususnya yang terkait praktik ibadah dan akhlak islami.

\section{DAFTAR PUSTAKA}

Mahmood, T. (1987). Family Law in Islamic Contries; History, Text and Comparative Analisys. New Delhi: Academy of Law and Religion.

Badan Pusat Statistik Kabupaten Gowa, Kecamatan Parigi dalam Angka Tahun 2019. Gowa: t.p 2019.

Komari dan Sunarsih. (2018). Panduan Belajar Baca Alquran Sistem Klasikal 20 Pertemuan DIROSA, Bogor; Yayasan Cita Mulia Mutiara.

Ali, M. M. (2001). The Concept of Modernization: An Analysis of Contemporary Islamic Thought. American Journal of Islamic Social Sciences, Vol. 14, No.1 (Spring 2001): p.13-26.

Muhammad Saddang, Achmad Abu Bakar, Munir. (2018). Implementasi Metode DIROSA dalam Pembelajaran Al-Qur'an Dewan Pimpinan Daerah Wahdah Islamiyah Makassar. Jurnal Diskursus Islam, Vol. 06, No.3 p.481-500.

Sekolah Tinggi Ilmu Islam dan Bahasa Arab (STIBA) Makassar, Visi misi, https://stiba.ac.id//tentangstiba/visi-misi/ (9 April 2020).

P3M STIBA Makassar. (2018). Buku Panduan KKN STIBA Makassar Angkatan II Tahun 1440 H/ 2018 M , Makassar: P3M STIBA Makassar. 